\title{
Feasibility and acceptability of an innovative adherence intervention for young adults with childhood-onset systemic Lupus Erythematosus
}

Onengiya Harry ${ }^{1,2^{*}}$, Lori E. Crosby ${ }^{3,4}$, Constance Mara ${ }^{3,4}$, Tracy V. Ting ${ }^{1,4}$, Jennifer L. Huggins $s^{1,4}$ and Avani C. Modi 3,4

\begin{abstract}
Background: In Childhood-Onset Systemic Lupus Erythematosus (CSLE), poor medication adherence rates are very high. Interventions targeting this problem in CSLE are limited thus effective interventions are needed. The objective of this study is to examine the feasibility and acceptability an intervention (automated digital reminders + personalized prescribed treatment plan (PPTP)) to improve medication adherence in young adults with cSLE over 3 months.

Method: This is a proof-of-concept randomized controlled study. All participants received SimpleMed+ pillboxes that track adherence. The treatment group received a pPTP, and in month 2, preselected digital reminders for missed doses. Reminders were discontinued after 30 days and adherence data collected. Data analysis was done using t-tests.

Results: Twenty-one participants were approached and nineteen consented to participate, yielding a recruitment rate of $86 \%$. Participants were on average 20.5 years, mostly black (58\%) and female (84\%). Of the nineteen consented, eleven were randomized to control (57\%) and eight to treatment (42\%) groups respectively. All participants in the treatment group rated the pillbox as easy to use, notably; none reported boredom with the pillbox or reminders. Also, $88 \%$ of participants in the treatment group rated the pillbox as helpful, however, only $50 \%$ reported the pPTP taught them new information about lupus or made them more interested in their lupus management.

Conclusions: This is the first use of an electronic pillbox to track adherence to multiple medications in CSLE. The high rating of the pillbox makes it an acceptable method of measuring adherence. Feasibility and acceptability ratings for the intervention were mixed suggesting a there is a subset of CSLE patients for whom this intervention would be beneficial. Future research should focus on a larger trial.
\end{abstract}

Keywords: Adherence intervention and young adults with cSLE, Adherence in CSLE, Adherence in pediatric-onset lupus, Adherence in CSLE

\footnotetext{
* Correspondence: oharry@wakehealth.edu

'Division of Rheumatology, Cincinnati Children's Hospital Medical Center,

Cincinnati, $\mathrm{OH}, \mathrm{USA}$

${ }^{2}$ Section of Pediatric Rheumatology, Department of Pediatrics, Brenner

Children's Wake Forest Baptist Health, Medical Center Boulevard, Winston

Salem, NC, USA

Full list of author information is available at the end of the article
}

(c) The Author(s). 2020 Open Access This article is licensed under a Creative Commons Attribution 4.0 International License, which permits use, sharing, adaptation, distribution and reproduction in any medium or format, as long as you give appropriate credit to the original author(s) and the source, provide a link to the Creative Commons licence, and indicate if changes were made. The images or other third party material in this article are included in the article's Creative Commons licence, unless indicated otherwise in a credit line to the material. If material is not included in the article's Creative Commons licence and your intended use is not permitted by statutory regulation or exceeds the permitted use, you will need to obtain permission directly from the copyright holder. To view a copy of this licence, visit http://creativecommons.org/licenses/by/4.0/ The Creative Commons Public Domain Dedication waiver (http://creativecommons.org/publicdomain/zero/1.0/) applies to the data made available in this article, unless otherwise stated in a credit line to the data. 


\section{Background}

In Childhood-Onset Systemic Lupus Erythematosus (cSLE), only $50-60 \%$ of patients take medications as prescribed [1]. Poor medication adherence (i.e. the extent to which an individual's behavior matches treatment regimens) contributes to the morbidity and mortality [2] experienced by those diagnosed with this chronic, autoimmune, multisystem, inflammatory condition. Unfortunately, poor adherence is associated with lower health-related quality of life, increased health care utilization, health care costs, and unnecessary medication changes [3-5]. Optimizing medication adherence in individuals with cSLE is critical because, compared with adult-onset SLE patients, they have a more severe and prolonged disease course with more disease-related organ damage [6].

Characteristics unique to cSLE make adherence particularly difficult, including number of medications, the complexity of medication regimens, medication-related organ damage, disease flares, and psychological manifestations $[7,8]$. For young adults with rheumatic diseases, adherence barriers include forgetfulness, polypharmacy, cost, personal problems, and/or refusal $[9,10]$. Specific to those with CSLE, medication-specific knowledge deficits and the lack of perceived improvement in daily symptoms are significant barriers to medication adherence $[2,10,11]$. In addition, real or perceived side effects, low medication literacy, and/or poor medication taste were identified as adherence barriers in CSLE. Unfortunately, adherence barriers are stable and unlikely to improve without interventions $[12,13]$.

Despite the need for adherence interventions in adolescents and young adults with cSLE, few exist. Ting et al. developed a cellular text messaging intervention to remind adolescents and young adults with cSLE to take their medications but found reminders alone ineffective [14]. In contrast, multicomponent interventions that include educational, behavioral, and/or organizational strategies produce medium effects to improve adherence $[15,16]$. A recent study by Scalzi and colleagues supports the use of multicomponent interventions in young adults with SLE [1]. In their study, participants were assigned to either a web-based educational module or a web-based educational module and social media intervention. Participants in the latter group showed significant improvement in medication adherence.

Our team developed a multicomponent adherence intervention targeting key adherence barriers identified by those with CSLE: medication-specific knowledge (i.e. goal of medication, regimen, side effects, and monitoring parameters) and forgetting. Personalized prescribed treatment plans have been found to improve diseasespecific knowledge in pediatric chronic conditions and subsequent adherence behaviors [17]. Automated digital reminders target the barrier of forgetting by reminding patients to take their medications at specified times using mobile devices and/or compartment lights and audible alarms [18]. Automated digital reminders have been show to significantly improve short term medication adherence in adult populations [19], but need to be further studied in adolescents and young adults whose information consumption patterns best align with technology use [20].

The primary objective of this proof of concept randomized controlled study was to assess the feasibility and acceptability of a multicomponent intervention focused on improving medication adherence in young adults with cSLE. The intervention included two primary components: a prescribed treatment plan to ensure patients were knowledgeable about their treatment regimen and automated digital reminders to help them remember to take their medications. We hypothesized that (1) participants would rate the intervention as easy to use, acceptable, and beneficial, and (2) medication adherence would improve in the treatment group (prescribed treatment plan plus digital reminders) from preto post-intervention and be sustained 1 month after completing the intervention compared to treatment as usual (control group).

\section{Methods}

\section{Study design and procedures}

Participants were randomized to one of two groups (i.e., control versus treatment). To minimize bias in the randomization process, a computer-generated table generated by the study's biostatistician determined the randomization scheme. Adherence was monitored by an electronic pillbox for both groups. While the control group received treatment as usual, the treatment group received a personalized prescribed treatment plan (pPTP) and automated digital reminders for 1 month.

At enrollment, participants (young adults) completed a battery of questionnaires and were given an electronic adherence pillbox (SimpleMed+, Vaica), which was used for the entire 3-month study period. A medical chart review was conducted at enrollment. At the end of the study, participants in the treatment group completed a feasibility and acceptability questionnaire within 2 weeks.

\section{Participants and recruitment}

Participants were recruited during routine pediatric rheumatology clinic visits at a Midwestern children's hospital. Inclusion/exclusion criteria were: 1) confirmed diagnosis of CSLE via chart or registry review, 2) patient between ages 18 and 24 years 3) English-speaking, and 4) no significant developmental delay or cognitive dysfunction (i.e. autism spectrum disorder). Eligible 
participants were approached by study staff at regularly scheduled clinic. All questions were addressed, and written informed consent was obtained. This study protocol was approved by the hospital's Institutional Review Board.

\section{Measures \\ Demographic information}

A demographic information questionnaire completed by young adults included patient's age, race, ethnicity, time to diagnosis, and year of diagnosis. Information regarding cSLE diagnosis, presence of lupus nephritis, SLE Disease Activity Index (SLEDAI), treatment regimen, and medical and psychosocial co-morbidities were abstracted from the electronic medical record (EMR).

\section{Barriers to Adherence Tool (BAT) [9]}

This fourteen item checklist assesses logistical, social, psychological and knowledge-based adherence barriers in patients for all treatment modalities (medications, injections, infusions and physical/occupational therapy) and was administered at baseline. While validation of this tool has not been done in CSLE, the themes represented by this measure have been scientifically validated in other chronic pediatric conditions [21].

\section{Pain intensity and fatigue}

Participants completed both the PROMIS ${ }^{\bullet}$ Pain Numeric Rating Scale v.1.0 (Pain Intensity 1a) and PROMIS Fatigue Short Form v1.0 (Fatigue 4a) at baseline to ensure no differences between the control and treatment groups. The Patient-Reported Outcomes Measurement Information System $\left(\mathrm{PROMIS}^{\circ}\right)$ is a set of validated, person-centered measures that standardize patient reported outcome assessment for use in both research and health care settings [18]. PROMIS ${ }^{\circ}$ consists of item banks with variable number of questions that can be combined to form multi-item measures of varying length and complexity $[18,19]$. Both measures employ a Likert-type scale. For pain intensity, a higher score denotes greater pain. For the PROMIS fatigue, a T-score is calculated in which 50 is the mean of a relevant reference population and 10 is the standard deviation of that population $[18,20]$. Higher $\mathrm{T}$ scores represent greater fatigue.

\section{Feasibility and acceptability}

This was assessed using: 1) enrollment and retention rates, 2) ability to utilize and return the electronic adherence monitoring device, 3) proportion of completed questionnaires, and 4) acceptability of the automated digital reminder and pPTP intervention as characterized by a written questionnaire.

\section{Feasibility and acceptability questionnaire}

This study-specific survey assessed feasibility and acceptability of the adherence intervention. The survey contains 12-items including information on ease of use, psychological benefits, and new knowledge about lupus, using a Likert-scale with scores ranging from 1 to 5 . A score of 4 and 5 indicated agreement or strong agreement with intervention features (e.g. ease of using pillbox or digital reminders). Similar questionnaires have been used by adherence researchers and provide critical information on ways to improve adherence interventions [22].

\section{Adherence outcomes \\ Medication adherence self report inventory (MASRI)}

The MASRI is a 6-item questionnaire of self-reported medication adherence assessing the frequency of medication intake and has been validated in patients with lupus $[23,24]$. Only the visual analog scale (VAS) item of the MASRI was used to determine a numeric estimate of adherence $(0-100 \%)$. This VAS has acceptable internal consistency (Cronbach's $\alpha=0.7$ ) and good reliability [24].

\section{Objective adherence}

All study participants were asked to use a SimpleMed+ pillbox to organize and administer their medications. The SimpleMed+ pillbox measures $17 \mathrm{~cm}$ (width) $\times 30.4$ $\mathrm{cm}$ (diameter) $\times 3.5 \mathrm{~cm}$ (height), with 28 compartments, enough to store up to four doses of multiple medications for each day of the week. This equipment has a selfcontained cellular modem, on-board reminders (compartment lights or sounds) and additional reminders (text messages) [18]. When a compartment is opened, a date/time stamp is sent wirelessly to a report that can be accessed on Vaica Medical's secure website.

\section{Study interventions \\ Usual care}

Participants received a standard after visit summary provided by their provider. Any questions regarding their visit plan or prescribed medications were addressed by their provider or nursing staff per customary clinic practice.

\section{Treatment}

Personalized prescribed treatment plan Participants in the treatment group received a tool designed by the authors to provide clear information regarding the individual's treatment plan in conjunction with their clinic after visit summary from the electronic medical record. Prior to use in study, feedback on the prescribed treatment plan was obtained from young adults with cSLE regarding clarity and content. This instrument contains 
Table 1 Baseline demographical, disease, and barriers characteristics of participants stratified by group

\begin{tabular}{|c|c|c|c|}
\hline Characteristic & $\begin{array}{l}\text { Total Participants } \\
(n=19)\end{array}$ & $\begin{array}{l}\text { Control } \\
(n=11)\end{array}$ & $\begin{array}{l}\text { Treatment } \\
(n=8)\end{array}$ \\
\hline \multicolumn{4}{|l|}{ Demographics } \\
\hline Age, mean, (SD) in yrs. & $20.5(1.6)$ & $20.5(1.6)$ & $20.5(1.7)$ \\
\hline Gender (female), No (\%) & $16(84)$ & $11(100)$ & $5(63)$ \\
\hline \multicolumn{4}{|l|}{ Race, No, (\%) } \\
\hline White & $6(32)$ & $4(36)$ & $2(25)$ \\
\hline Black & $11(58)$ & $6(55)$ & $5(63)$ \\
\hline Asian & $1(5)$ & - & $1(13)$ \\
\hline Multiple & $1(5)$ & $1(9)$ & - \\
\hline \multicolumn{4}{|l|}{ Insurance type, No (\%) } \\
\hline Public & $7(37)$ & $5(45)$ & $2(25)$ \\
\hline Private & $12(63)$ & $6(55)$ & $6(75)$ \\
\hline \multicolumn{4}{|l|}{ cSLE } \\
\hline Disease duration, yrs., (SD) & $4.8(3.2)$ & $4(3)$ & $5.4(3.4)$ \\
\hline SLEDAl ${ }^{a}$, mean, (range) & $5(0-10)$ & $5(2-10)$ & $4.4(0-9)$ \\
\hline SLICC, No., (\%) & $4(40)$ & $3(30)$ & $1(12.5)$ \\
\hline Physician global, mean (range) & $0.9(0-3.5)$ & $1(0-3.5)$ & $0.6(0-1.5)$ \\
\hline Nephritis, No. (\%) & $8(42)$ & $5(45)$ & $3(38)$ \\
\hline PROMIS fatigue, mean (SD) & $53 \pm 3.0$ & $57 \pm 2.9$ & $47 \pm 3.2$ \\
\hline PROMIS pain intensity, mean (SD) & $2.8(2.3)$ & $3.6 \pm 2.3$ & $1.8(1.9)$ \\
\hline No of Pills ${ }^{c}$, mean (SD) & $7(3.8)$ & $7(3.5)$ & $8(4.2)$ \\
\hline Presence of comorbidity (\%) & $18(95)$ & $11(100)$ & $7(88)$ \\
\hline Hypertension, No. (\%) & $5(26)$ & $3(27)$ & $2(25)$ \\
\hline Depression, No. (\%) & $5(26)$ & $3(27)$ & $2(25)$ \\
\hline Obesity, No. (\%) & $10(53)$ & $7(66)$ & $3(38)$ \\
\hline \multicolumn{4}{|l|}{ Barriers $^{\mathrm{d}}$, No (\%) } \\
\hline Forgetting & $15(79)$ & $11(100)$ & $4(50)$ \\
\hline Taste & $13(68)$ & $9(81)$ & $4(50)$ \\
\hline \multicolumn{4}{|l|}{ Side effects } \\
\hline Current & $12(63)$ & $8(73)$ & $4(50)$ \\
\hline Future & $11(58)$ & $6(55)$ & $5(63)$ \\
\hline Fertility concerns & $11(58)$ & $7(64)$ & $4(50)$ \\
\hline Treatment upsetting & $8(42)$ & $6(55)$ & $2(25)$ \\
\hline Inconvenient & $7(37)$ & $6(55)$ & $1(13)$ \\
\hline Cost & $7(37)$ & $5(45)$ & $2(25)$ \\
\hline
\end{tabular}

${ }^{a}$ SLEDAI $2 \mathrm{~K}$ score from clinic visit preceding start of study

${ }^{\mathrm{b}}$ SLICC Damage Index obtained from annual calculated score within 12 months of study initiation

Includes both lupus and non-lupus medications being taken by participants

Includes barriers with fewer than 3 respondents such as difficulty swallowing pills, running out of medication, refusing to take treatment, believing treatment to

be unnecessary, desire to keep treatment private from others, lack of perceived treatment benefit, treatment getting in the way, and hard instructions

information about medication by functional classification (i.e. core medication $=$ hydroxychloroquine, fastacting immune suppressant $=>$ steroids, etc.). The prescribed treatment plan also includes an "other" category which covers vaccines, supplements, contraceptives, information on adverse effects and monitoring parameters for each class. Participants were oriented to the treatment plan and all of their medications were documented (including dosage and timing). All questions regarding the prescribed treatment plan were answered by the first author.

Automated digital reminders The treatment group also received automated digital reminders for 30 days 
beginning in month 2 of the study. Participants could select up to 3 automated digital reminders (i.e. text messages, compartment lights, or sound); all but one participant chose text messages. During the active treatment period (month 2), automated digital reminders began for the treatment group while control participants continued to use their electronic monitors without receiving reminders. At the beginning of month 3 , the automatic digital reminders were turned off for the treatment group. Study personnel accessed Vaica Medical's secure website three times a week to record logged adherence information.

\section{Statistical analysis}

Data analytic procedures were carried out using SAS version 9.4 (SAS Institute Inc., Cary, NC). Data were entered and cross-checked for accuracy. Descriptive statistics (e.g. frequency, mean, range, SD) were calculated for demographic, disease severity, self-reported adherence, and feasibility/acceptability variables. Two sample independent $\mathrm{t}$-tests were used to examine differences between control and treatment groups at baseline.

Adherence was calculated as the number of doses taken/number of doses prescribed " $100 \%$ as measured by the adherence monitors. Adherence ranged from 0 to $100 \%$ for all analyses [22, 25]. A power analysis was not calculated as the primary aims of this study were feasibility and acceptability of this intervention.

\section{Results}

\section{Baseline demographic and disease parameters}

Demographical and disease characteristics are summarized in Table 1. Overall, participants were on average 20.5 years (32\% White; 58\% Black; $1 \%$ Asian; $1 \%$ multiple races; $84 \%$ female; and $16 \%$ male). All participants had at least four of the 11 ACR classification criteria for SLE at time of diagnosis. Forgetting to take medication, medication side effects, fertility concerns, and taste of medication were top barriers to medication adherence (see Table 1). At baseline, control and treatment groups were similar except the control group had more female participants $(p<0.03)$, more fatigue $(p<0.001)$, and endorsed forgetting to take medications $(p=0.01)$ as a barrier to medication adherence more often. There was no significant difference in self-report of adherence (MASRI adherence score, $p=0.73$ ), proportion with organ damage $(p=0.38)$, or pain intensity $(p=0.25)$.

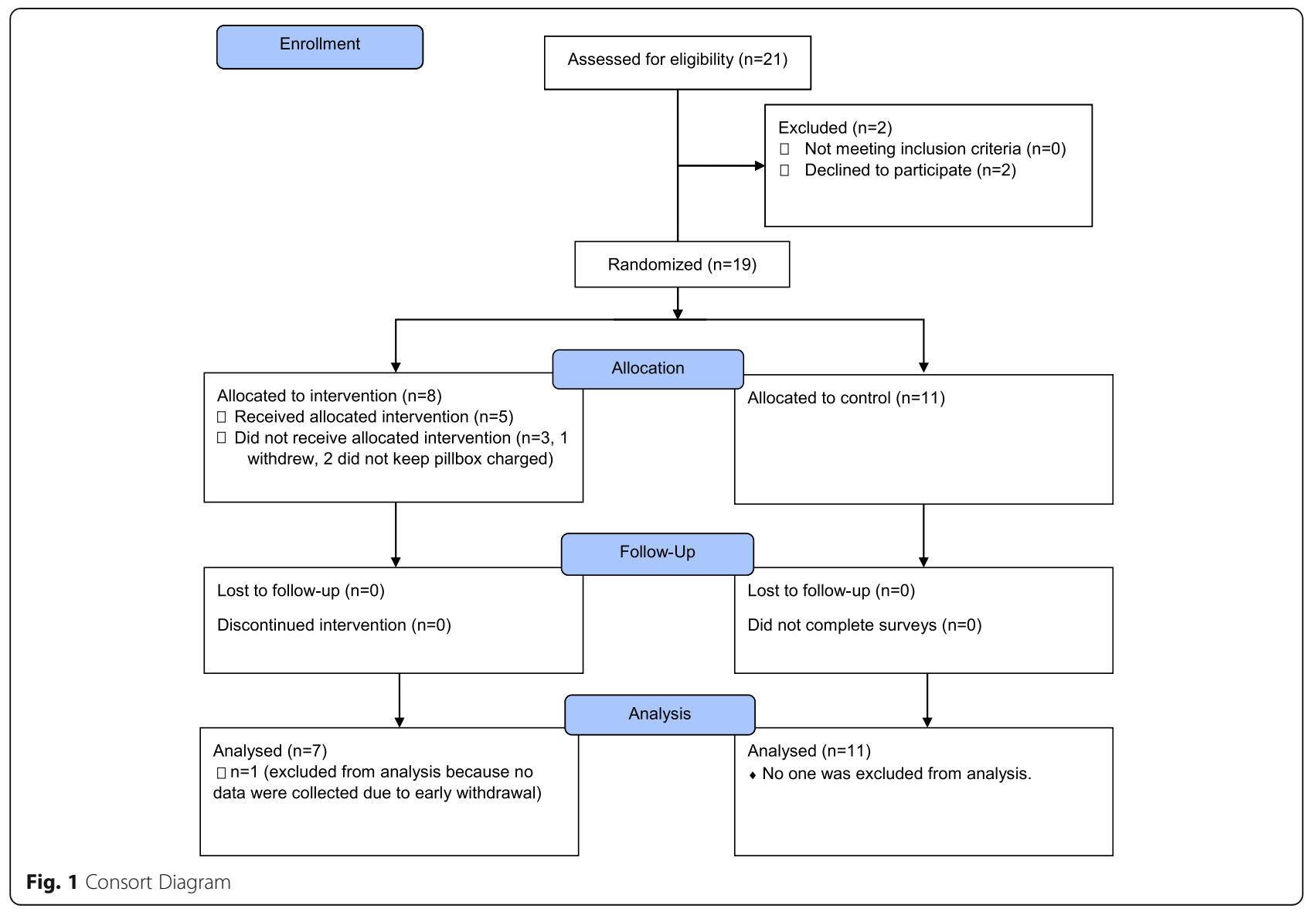




\section{Feasibility and acceptability parameters}

Twenty-one participants were approached for participation and nineteen consented to participate (see Fig. 1, Consort Diagram). Two individuals declined study participation yielding a recruitment rate of $86 \%$. Reasons for non-participation were having only one medication daily and no desire to participate. Of the nineteen who consented, eleven were randomized to treatment as usual (57\%) and eight were randomized to treatment (42\%). Once allocated to groups, three participants in the treatment group did not receive the intervention (1 participant withdrew due to problems with equipment connectivity despite changing pillboxes and 2 participants did not keep the pillbox charged for monitoring). No participants were lost to follow up at study completion; however, the participant who withdrew was not included in objective adherence analyses.

Eighteen of nineteen participants completed all components of the study, used the pillbox, and returned it at study completion. Notably, all participants completed study questionnaires. Eighty-eight percent (7/8) of the treatment group actively used their SimpleMed+ pillbox. None of the participants in treatment group reported boredom with the pillbox or reminders. Responses on the feasibility and acceptability questionnaire are summarized in Table 2.

\section{Objective adherence outcomes}

Objective adherence. Baseline objective adherence was different for both control and treatment groups despite randomization. The control group also had a steep decline in objective adherence that continued over the duration of the study (Fig. 2 -Means of Objective Adherence over Time). Notably, mean objective adherence for the treatment group continued to increase although this increase was not statistically significant (63 to $66, p=$ n.s.).

\section{Discussion}

This proof-of-concept study of a multicomponent adherence intervention, focused on providing education about the individual's treatment regimen and automated digital reminders to young adults with cSLE. Participants were able to use the pillbox and ensure cellular connectivity with minimal guidance. The high use and acceptability rating of the pillbox suggests that it a feasible and acceptable method of measuring objective adherence as an outcome measure for future trials. In contrast, acceptability ratings for the multi-component adherence intervention were mixed. While none of the participants became bored with the pillbox and reminders, only half of the responders rated the intervention highly favorable. Higher acceptability may have been reported by the $50 \%$ of participants who identified forgetting as a primary
Table 2 Feasibility and acceptability results for the treatment group

\begin{tabular}{|c|c|}
\hline Title Items & $\begin{array}{l}\text { \% Young Adult Who Agree } \\
\text { or Strongly Agree }{ }^{\mathbf{a}} \\
(\boldsymbol{N}=8)\end{array}$ \\
\hline 1. The pillbox was easy to use. & 100 \\
\hline 2. The pillbox did not have any glitches. & $75^{\mathrm{b}}$ \\
\hline 3. The pillbox was helpful. & 88 \\
\hline $\begin{array}{l}\text { 4. The personalized treatment plan } \\
\text { taught me something new. }\end{array}$ & 50 \\
\hline $\begin{array}{l}\text { 5. The personalized treatment plan made } \\
\text { me more interested in my lupus } \\
\text { management. }\end{array}$ & 50 \\
\hline
\end{tabular}

$\%$ Young Adult Who Agree or Strongly Agree $^{a}$ $(N=5)$

6. The pillbox plus digital reminders $\quad 60$

helped me take my lupus medicine.

7. I took my medication as soon as the $\quad 40$ reminders alerted me.

8. The reminders were useful to my lupus 60 management.

9. I became bored with pillbox and 0 reminders.

10. I will continue to use the pillbox with 60 reminders in the future.

11. Overall, I benefited from using the pillbox with reminders.

12. I think the pillbox with reminders has helped reduce my stress about managing lupus.

${ }^{\mathrm{a}}$ Based on a 4-5 score on a 5 point Likert Scale denoting agree or strongly agree. Assumption is made that a rating in this range notes a high rate of acceptability by respondents

bone participant had difficulty with pillbox cellular connectivity. The other participant chose a "neutral" response but had previously reported problems with not having electricity at home

adherence barrier. This finding suggests that there is a subset of cSLE patients for whom an electronic pillbox with digital reminders would be beneficial. Half of the participants in the treatment group reported gaining new lupus-related knowledge and being more interested in the management of their lupus from the pPTP. This indicates that although education in general is helpful, educational interventions should be personalized to address specific knowledge deficits (i.e. side effects or fertility concerns). Overall, this multicomponent intervention warrants further study for the subset of patients for whom forgetting and certain medication-related knowledge deficits are significant barriers to medication adherence. Future studies should tailor interventions to more precisely target individual barriers to medication adherence.

Our objective adherence data suggests group differences in adherence, with the treatment group having 


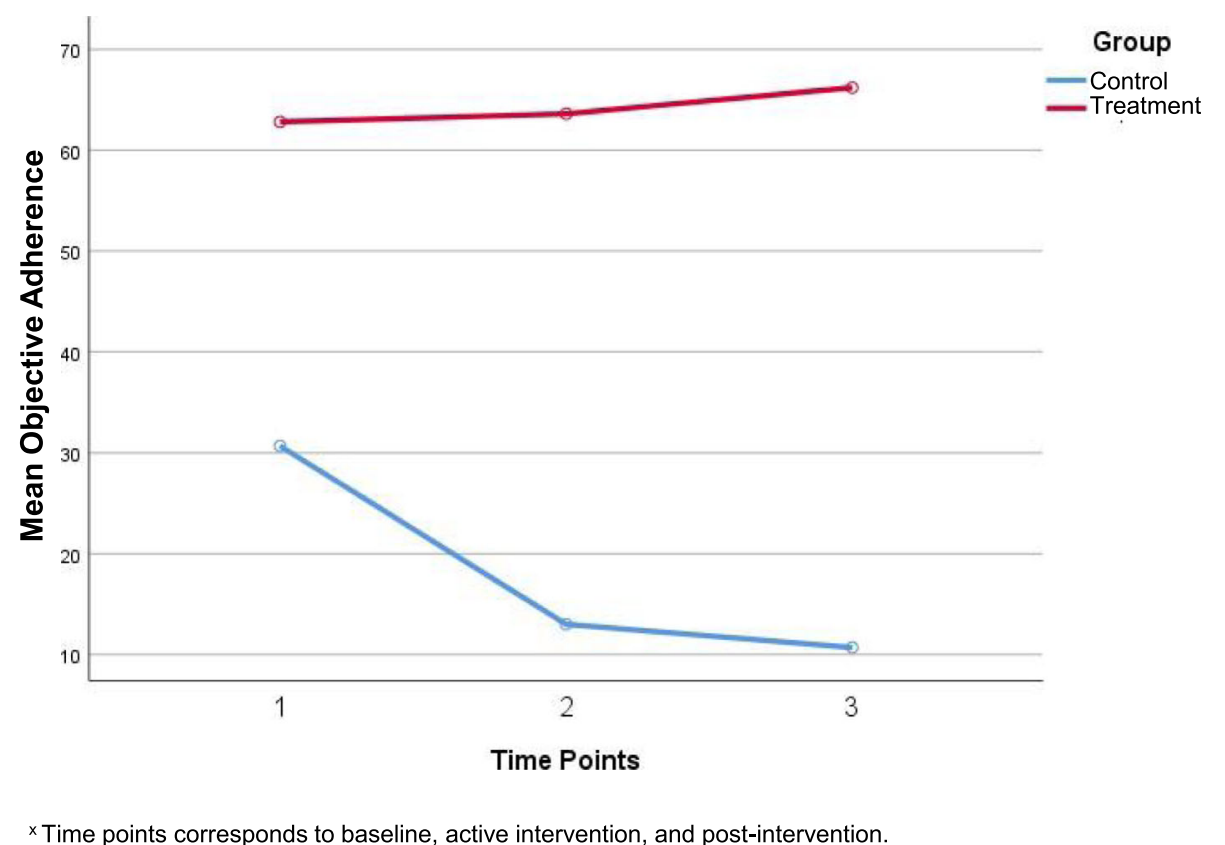

Fig. 2 Means of Objective Adherence over Time

higher adherence over time compared to the control group. Reasons for this group difference may be explained by expected reactivity to intervention. The effect of typical reactivity to the pillbox at baseline remains unclear for the treatment group. However, objective adherence for the control group shows a steep decrease from the first to second month suggesting a 4 week period of typical reactivity to the pillbox and/or intervention. This finding is consistent with adherence interventions in chronic illnesses [22, 25].

For the control group, objective adherence continued to decline over the duration of the study indicating that poor adherence to medication may not improve without intervention. A similar trend has been reported for those with poor medication adherence, without targeted intervention, in other chronic conditions [12, 26, 27].

While there were promising insights from this proofof-concept study targeting a complex problem, we acknowledge a number of potential limitations. First, our sample size was small and thus we may have been underpowered to detect changes over time between groups. However, the main purpose of this study was to assess the feasibility and acceptability of using electronic pillboxes, provision of a personalized treatment plan and automated digital reminders. Second, this was a single site study that focused only on young adults, a high risk population for poor medication adherence, which may impact generalizability of results. Finally, although essential for unbiased group allocation, our randomization was not stratified to have equal groups due to the small sample size.

\section{Conclusion}

Overall, our study indicates that electronic pillboxes are easy to use and may be used to track adherence in future studies, especially for those on multiple medications. Further research is needed to assess the correlation between this pillbox and other measures of adherence such as medication possession ratio or proportion days covered. Also, large-scale testing of the electronic pillbox with automated digital reminders as an adherence intervention for patients with cSLE is needed to detect effect sizes. If effective, this methodology has promise to increase medication adherence thereby decreasing negative health outcomes associated with poor adherence. Finally, continued clinical research that results in a refined approach to optimize the intervention by using the most effective components will be required to realize the full potential of electronic pillboxes for improving medication adherence in adolescents and young adults with cSLE.

\section{Abbreviations \\ ACR: American College of Rheumatology; ANOVA: Analysis of Variance; BAT: Barriers to Adherence Tool; cSLE: Childhood-Onset Systemic Lupus Erythematosus; EMR: Electronic Medical Record; MASRI: Medication Adherence Self-Report Inventory; PROMIS ${ }^{\odot}$ : Patient-Reported Outcomes Measurement Information System; SAS: Statistical Analysis System; SLE: Systemic Lupus Erythematosus; SLEDAl: SLE Disease Activity Index; pPTP: Personalized Prescribed Treatment Plan; VAS: Visual Analogue Scale}

\section{Acknowledgements}

The authors would like to thank all of the patients without whose participation this work would not be possible. Also, we will like to thank Dr. Hermine Brunner for her general support toward this research project. 


\section{Authors' contributions}

$\mathrm{OH}, \mathrm{AM}, \mathrm{LC}, \mathrm{TT}, \mathrm{CM}$, and $\mathrm{JH}$ all contributed to study design. $\mathrm{OH}, \mathrm{JH}$, and $\Pi$ coordinated enrollment and data collection. OH, CM, LC, T, and AM analyzed and interpreted the data. All authors were contributors to the writing of the manuscript and formation of tables and figures. All authors read and approved the final manuscript.

\section{Funding}

The research was supported by a T32 HD 68223-6 A1, Kirschstein-NRSA training grant to the first author.

\section{Availability of data and materials}

The datasets generated and/or analyzed during the current study are not publicly available due to the restrictions of the ethics approval originally obtained.

\section{Ethics approval and consent to participate}

This study received Institutional Review Board Approval (\#2018-3362)

through Cincinnati Children's Hospital Medical Center.

\section{Consent for publication}

All young adults who were enrolled completed a written consent to participate and have this work published.

\section{Competing interests}

The authors declare that they have no competing interests.

\section{Author details}

${ }^{1}$ Division of Rheumatology, Cincinnati Children's Hospital Medical Center, Cincinnati, OH, USA. ${ }^{2}$ Section of Pediatric Rheumatology, Department of Pediatrics, Brenner Children's Wake Forest Baptist Health, Medical Center Boulevard, Winston Salem, NC, USA. ${ }^{3}$ Division of Behavior Medicine and Clinical Psychology, Cincinnati Children's Hospital Medical Center, Cincinnati, $\mathrm{OH}$, USA. ${ }^{4} \mathrm{College}$ of Medicine, University of Cincinnati, Cincinnati, OH, USA.

\section{Received: 29 October 2019 Accepted: 17 April 2020}

\section{Published online: 26 April 2020}

\section{References}

1. Scalzi LV, Hollenbeak CS, Mascuilli E, Olsen N. Improvement of medication adherence in adolescents and young adults with SLE using web-based education with and without a social media intervention, a pilot study. Pediatr Rheumatol Online J. 2018;16(1):18.

2. Bugni VM, Ozaki LS, Okamoto KY, Barbosa CM, Hilário MO, Len CA, et al. Factors associated with adherence to treatment in children and adolescents with chronic rheumatic diseases. J Pediatr. 2012:88(6):483-8.

3. Costedoat-Chalumeau N, Pouchot J, Guettrot-Imbert G, Le Guern V, Leroux G, Marra D, et al. Adherence to treatment in systemic lupus erythematosus patients. Best Pract Res Clin Rheumatol. 2013;27(3):329-40.

4. Prados-Moreno S, Sabio JM, Perez-Marmol JM, Navarrete-Navarrete N, Peralta-Ramirez MI. Adherence to treatment in patients with systemic lupus erythematosus. Med Clin (Barc). 2018;150(1):8-15

5. McGrady ME, Hommel KA. Medication adherence and health care utilization in pediatric chronic illness: a systematic review. Pediatrics. 2013;132(4):730-40.

6. Aggarwal A, Srivastava P. Childhood onset systemic lupus erythematosus: how is it different from adult SLE? Int J Rheum Dis. 2015;18(2):182-91.

7. Harris JG, Maletta Kl, Kuhn EM, Olson JC. Evaluation of quality indicators and disease damage in childhood-onset systemic lupus erythematosus patients. Clin Rheumatol. 2017:36(2):351-9.

8. Davis AM, Graham TB, Zhu Y, McPheeters ML. Depression and medication nonadherence in childhood-onset systemic lupus erythematosus. Lupus. 2018;27(9):1532-41.

9. Favier LA, Taylor J, Loiselle Rich K, Jones KB, Vora SS, Harris JG, et al. Barriers to adherence in juvenile idiopathic arthritis: a multicenter collaborative experience and preliminary results. J Rheumatol. 2018;45(5):690-6.

10. Harry O, Crosby LE, Smith AW, Favier L, Aljaberi N, Ting TV, et al. Selfmanagement and adherence in childhood-onset systemic lupus erythematosus: what are we missing? Lupus. 2019;28:642-50. https://doi. org/10.1177/0961203319839478.
11. Costedoat-Chalumeau N, Tamirou F, Piette JC. Treatment adherence in systemic lupus erythematosus and rheumatoid arthritis: time to focus on this important issue. Rheumatology. 2018;57(9):1507-9.

12. Ramsey RR, Zhang N, Modi AC. The stability and influence of barriers to medication adherence on seizure outcomes and adherence in children with epilepsy over 2 years. J Pediatr Psychol. 2018;43(2):122-32.

13. Simons LE, McCormick ML, Devine K, Blount RL. Medication barriers predict adolescent transplant recipients' adherence and clinical outcomes at 18month follow-up. J Pediatr Psychol. 2010;35(9):1038-48.

14. Ting TV, Kudalkar D, Nelson S, Cortina S, Pendl J, Budhani S, et al. Usefulness of cellular text messaging for improving adherence among adolescents and young adults with systemic lupus erythematosus. J Rheumatol. 2012;39(1): 174-9.

15. Graves MM, Roberts MC, Rapoff M, Boyer A. The efficacy of adherence interventions for chronically ill children: a meta-analytic review. J Pediatr Psychol. 2010;35(4):368-82

16. Kahana S, Drotar D, Frazier T. Meta-analysis of psychological interventions to promote adherence to treatment in pediatric chronic health conditions. J Pediatr Psychol. 2008;33(6):590-611.

17. levers CE, Brown RT, Drotar D, Caplan D, Pishevar BS, Lambert RG. Knowledge of physician prescriptions and adherence to treatment among children with cystic fibrosis and their mothers. J Dev Behav Pediatr. 1999; 20(5):335-43.

18. McGrady ME, Holbein CE, Smith AW, Morrison CF, Hommel KA, Modi AC, et al. An independent evaluation of the accuracy and usability of electronic adherence monitoring devices. Ann Intern Med. 2018;169(6):419-22.

19. Park LG, Howie-Esquivel J, Dracup K. A quantitative systematic review of the efficacy of mobile phone interventions to improve medication adherence. J Adv Nurs. 2014;70(9):1932-53.

20. Lenhart A Teens, social media \& technology overview 2e015. 2015 Accessed last June 21, 2019. Available from: www.pewinternet.org/files/2015/04/PI_ TeensandTech_Update2015_0409151.pdf

21. Modi AC, Monahan S, Daniels D, Glauser TA. Development and validation of the pediatric epilepsy medication self-management questionnaire. Epilepsy Behav. 2010;18(1-2):94-9.

22. Favier LA, Ting TV, Modi AC. Feasibility of a musculoskeletal ultrasound intervention to improve adherence in juvenile idiopathic arthritis: a proof-of concept trial. Pediatr Rheumatol Online J. 2018;16(1):75.

23. Koneru S, Kocharla L, Higgins GC, Ware A, Passo MH, Farhey YD, et al. Adherence to medications in systemic lupus erythematosus. J Clin Rheumatol. 2008;14(4):195-201.

24. Koneru S, Shishov M, Ware A, Farhey Y, Mongey AB, Graham TB, et al. Effectively measuring adherence to medications for systemic lupus erythematosus in a clinical setting. Arthritis Rheum. 2007:57(6):1000-6.

25. Modi AC, Guilfoyle SM, Rausch J. Preliminary feasibility, acceptability, and efficacy of an innovative adherence intervention for children with newly diagnosed epilepsy. J Pediatr Psychol. 2013;38(6):605-16.

26. Gutierrez-Colina AM, Smith AW, Mara CA, Modi AC. Adherence barriers in pediatric epilepsy: from toddlers to young adults. Epilepsy Behav. 2018;80: 229-34

27. Feldman $\mathrm{CH}$, Collins J, Zhang Z, Subramanian SV, Solomon DH, Kawachi I, et al. Dynamic patterns and predictors of hydroxychloroquine nonadherence among Medicaid beneficiaries with systemic lupus erythematosus. Semin Arthritis Rheum. 2018;48(2):205-13.

\section{Publisher's Note}

Springer Nature remains neutral with regard to jurisdictional claims in published maps and institutional affiliations. 